\title{
Traits to ecosystems: the ecological sustainability challenge when developing future energy crops
}

\author{
Martin Weih $^{1}{ }^{*}$, Stefanie Hoeber ${ }^{1}$, Friderike Beyer ${ }^{1}$ and Petra Fransson ${ }^{2}$ \\ ${ }^{1}$ Department of Crop Production Ecology, Swedish University of Agricultural Sciences, Uppsala, Sweden \\ ${ }^{2}$ Department of Forest Mycology and Plant Pathology, Swedish University of Agricultural Sciences, Uppsala, Sweden
}

\section{Edited by:}

Junye Wang, Athabasca University,

Canada

Reviewed by:

Jennifer Cunniff, Rothamsted

Research, UK

Peter Spathelf, Eberswalde University

for Sustainable Development,

Germany

*Correspondence:

Martin Weih, Department of Crop

Production Ecology, Swedish

University of Agricultural Sciences

(SLU), P.O. Box 7043, SE-750 07

Uppsala, Sweden

e-mail:martin.weih@slu.se
Today, we are undertaking great efforts to improve biomass production and quality traits of energy crops. Major motivation for developing those crops is based on environmental and ecological sustainability considerations, which however often are de-coupled from the trait-based crop improvement programs. It is now time to develop appropriate methods to link crop traits to production system characteristics set by the plant and the biotic communities influencing it; and to the ecosystem processes affecting ecological sustainability. The relevant ecosystem processes involve the net productivity in terms of biomass and energy yields, the depletion of energy-demanding resources (e.g., nitrogen, N), the carbon dynamics in soil and atmosphere, and the resilience and temporal stability of the production system. In a case study, we compared aspects of $\mathrm{N}$ use efficiency in various varieties of an annual (spring wheat) and perennial (Salix) energy crop grown under two nutrient regimes in Sweden. For example, we found considerable variation among crops, varieties, and nutrient regimes in the energy yield per plant-internal $\mathrm{N}$ (megajoule per gram per year), which would result in different $\mathrm{N}$ resource depletion per unit energy produced.

Keywords: biomass crops, ecological sustainability, mycorrhiza, nitrogen use efficiency, resilience, Salix, soil carbon, wheat

\section{INTRODUCTION}

Biomass has the potential to become one of the major global primary energy sources in the future, and agricultural crops are projected to become the largest source of biomass for energy (Berndes et al., 2003). Biomass derived from bioenergy crops is expected to play an important role in combating global climate change, and the increased share of renewable energy sources is therefore motivated mainly by means of environmental benefits and increased ecological sustainability (Karp and Shield, 2008; Kotchoni and Gachomo, 2008). In addition, plantations of fastgrowing crops offer great possibilities for environmental control at a local scale in terms of, e.g., phytoremediation. Thus, based on the large nutrient quantities taken up by fast-growing biomass crops, the plantations can be used as recipients for municipal wastewater and industrial sludge and simultaneous biomass production (multifunctional biomass plantations, Perttu, 1993; Isebrands and Karnosky, 2001). To improve yields, expand cultivation areas and facilitate new uses, there are currently great crop breeding efforts undertaken to develop new energy crops and crop cultivars with improved biomass yield and quality traits (Davidson, 2008; Jaradat, 2010); and including all new technologies to accelerate breeding toward increased agronomic performance (Tester and Langridge, 2010). Crop breeding is strictly trait-based and usually targets relatively short-term events occurring in more or less simple systems, whereas the ecological sustainability evaluation requires the integration of longer-term ecological processes occurring in complex systems (Weih et al., 2008). In ecology, linking traits to ecosystem processes has been discussed within the context of community or ecosystem genetics, which refers to the study of genetic interactions among genotypes and their abiotic environment in complex communities (Whitham et al., 2006). However, the community genetics research usually focuses on the loss of genotypes and the prediction of the consequences of that loss for biodiversity and ecosystem function (cf., Schwartz et al., 2000). Here, we suggest applying such an approach to learn about the consequences of the addition of new genotypes of energy crops for ecosystem function and the ecological sustainability of bioenergy systems. Ideally, a trait-to-ecosystem perspective should be integrated into the breeding research for energy crops, for which the environmental performance is of uppermost importance. In that perspective, the cascading effects of crop characteristics targeted in plant breeding research on the ecosystem processes particularly important in the evaluation of the ecological sustainability of energy crops should be considered (Figure 1).

\section{PRODUCTIVITY AND RESOURCE DEPLETION}

Enhanced biomass yield and productivity are the most prominent targets in energy crop breeding research, apart from biomass quality traits affecting biomass processing (Jaradat, 2010). In recent years, increased yield stability under adverse abiotic (e.g., drought and salinity) and biotic (pests, diseases) conditions are gaining increased attention. In an energy crop context, sustainability in biomass production would aim at enhanced energy output with maintained or reduced depletion of natural resources, e.g., sustainability sensu the ability to be sustained by not depleting natural resources (Anonymous, 2013). Reduced resource depletion is thus an important element in sustainable agriculture and forestry (Higman et al., 2005; Brodt et al., 2011), and needs to be linked to the 


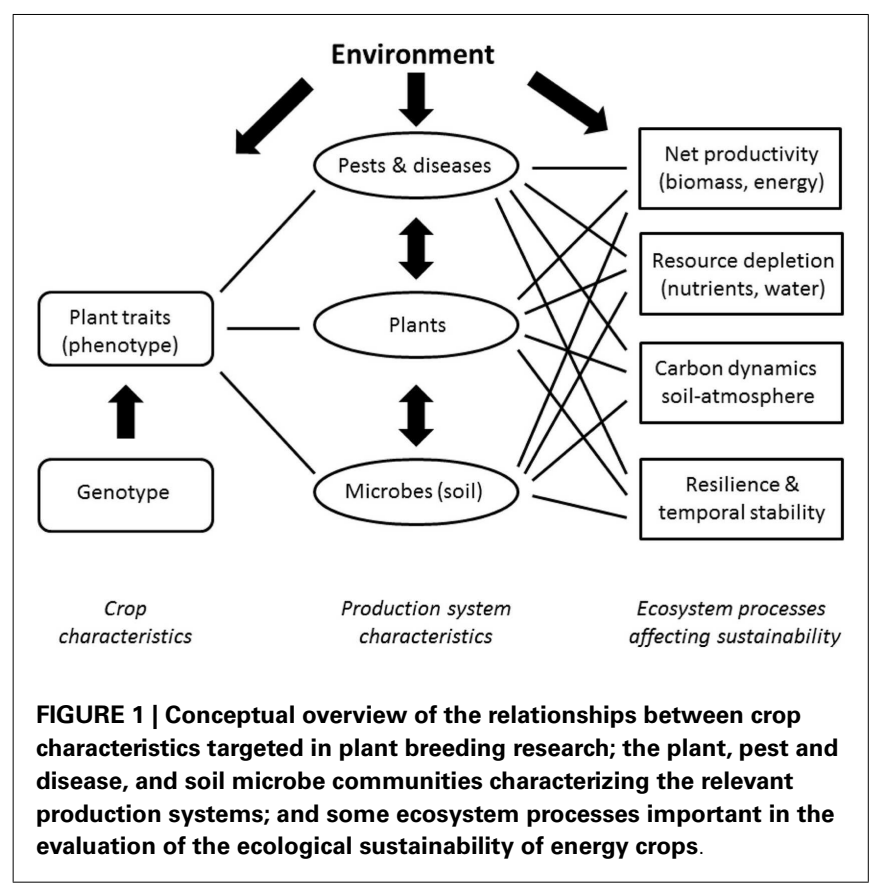

crop productivity traits often targeted in breeding research (e.g., Figure 1). Apart from water, the availability of mineral nutrients and particularly nitrogen $(\mathrm{N})$ is the most growth-limiting factor in crop production, and the manufacture of commercial fertilizers consumes much energy and thereby contributes to global warming. As a matter of fact, enhanced biomass production is usually associated with increased $\mathrm{N}$ absorption from the soil (Kaien et al., 2012). Also, crop breeding research targeting nutrient use efficiency often focuses on increased nutrient uptake rates (to increase yield), which is not in line with the sustainability aim of reduced resource depletion. There are various approaches for assessment of nutrient use efficiency in plants and crops (review by Weih et al., 2011). The evaluation of biomass productivity in relation to nutrient resource use is facilitated by the separation of three general aspects: the nutrient uptake efficiency; the efficiency at which the accumulated plant-internal nutrients are converted to biomass; and the nutrient re-translocation efficiency. Weih et al. (2011) have developed a flexible concept involving those three aspects and applicable to annual and perennial crops for various uses, among them energy conversion.

To illustrate a resource-oriented perspective on energy crops, we have on an annual basis compared the $\mathrm{N}$ use efficiency aspects (sensu Weih et al., 2011) in an annual (wheat) and perennial (biomass willow, first rotation, third year) crop with anticipated use for energy conversion based on current commercial practices in Sweden (ethanol production; Börjesson and Tufvesson, 2011) (Figure 2). The initial amount of plant-N present in the production system through seed grain (wheat) or previous year biomass (willow) was as expected considerably higher in the willow system (third year growth), especially when fertilized the previous year (Figure 2A). The total $\mathrm{N}$ amount accumulated by the crop during main growth period was lowest in unfertilized willow, but similar for the fertilized willow and wheat (Figure 2B). Consequently, the
$\mathrm{N}$ uptake efficiency during main growth period was much higher in wheat and considerably enhanced when the crop was fertilized (Figure 2C). Nutrient fertilization greatly enhanced crop yields (not shown), but decreased the crop-N-based biomass yield (yield specific N efficiency; Figure 2D), reflecting the general pattern of more than proportional resource demand when crop yields are increased through fertilization (Tilman et al., 2002). Taken together, the perennial willow system produced a greater amount of biomass per unit $\mathrm{N}$ accumulated at similar or lower total $\mathrm{N}$ accumulation than the annual wheat system. The $\mathrm{N}$ concentration and $\mathrm{N}$ amount in the harvested biomass (grain or shoots) is greater in wheat (Figure 2E), resulting in lower energy output per unit $\mathrm{N}$ lost from the system through harvest compared to the willow (Figure 2F).

In an ecological sustainability context, a major breeding focus for energy crops could be enhanced energy output per $\mathrm{N}$ resource depletion, e.g., the N-based energy ratio presented in Figure 2F, and the identification of heritable traits affecting it. This ratio is expected to be influenced by various crop characteristics, e.g., the yield specific $\mathrm{N}$ efficiency (Figure 2D) and quality traits such as the $\mathrm{N}$ concentration of the harvested biomass (Figure 2E). The yield specific $\mathrm{N}$ efficiency is expected to be enhanced through the traits optimizing canopy architecture and photosynthesis (Long et al., 2006; Weih and Rönnberg-Wästljung, 2007), and also the traits confining a capacity of the crop to be grown as a perennial. The great genotypic variation in for instance $E_{\mathrm{N}}$, energy and $C_{\mathrm{N} \text {, yield }}$ seen in Figure 2 (the error bars indicate ranges across six cultivar means) indicates opportunities for breeding, and additional breeding opportunities could arise from the possible genotypic variation in heating value not considered here. Apart from crop traits, management actions affecting the interaction between plants, e.g., plant spacing, variety mixture, sensitivity to pests and diseases, and the abundance of weeds competing for soil nutrients will also affect the $E_{\mathrm{N} \text {, yield }}$ and thereby the N-based energy ratio of the crop.

The $\mathrm{N}$ re-translocation efficiency, here documented as $\mathrm{N}$ concentrations of the harvested biomass (Figure 2E) reveals an interesting difference between the two crops when used for energy conversion. In cereals like wheat, the annually harvested grain, here assumed to be the only plant part used for energy conversion, is also the only surviving plant part in which the plant-internal $\mathrm{N}$ can be translocated during crop maturation, resulting in relatively high grain $\mathrm{N}$ concentrations. In perennial crops like willow, the plantinternal $\mathrm{N}$ is repeatedly re-translocated between leaves, shoots, and roots, before shoots are harvested every third or fourth year for energy conversion, and $\mathrm{N}$ concentrations in harvested plant parts are much lower than in wheat. In a sustainability perspective, the differences between wheat and willow in the $\mathrm{N}$ content of the biomass used for energy conversion (Figure 2E) are relevant, mainly because higher $\mathrm{N}$ contents in the processed biomass affect greenhouse gas balance, e.g., through increased $\mathrm{NO}_{\mathrm{x}}$ emissions (Börjesson and Tufvesson, 2011).

Compared to a traditional focus on biomass yields and qualities, a resource-oriented approach adds a resource dimension that can be helpful in the evaluation of energy crops within an ecological sustainability context. The example illustrates how trait-based breeding research for energy crops could gain from a shift in perspective - from today's predominant focus on isolated biomass 

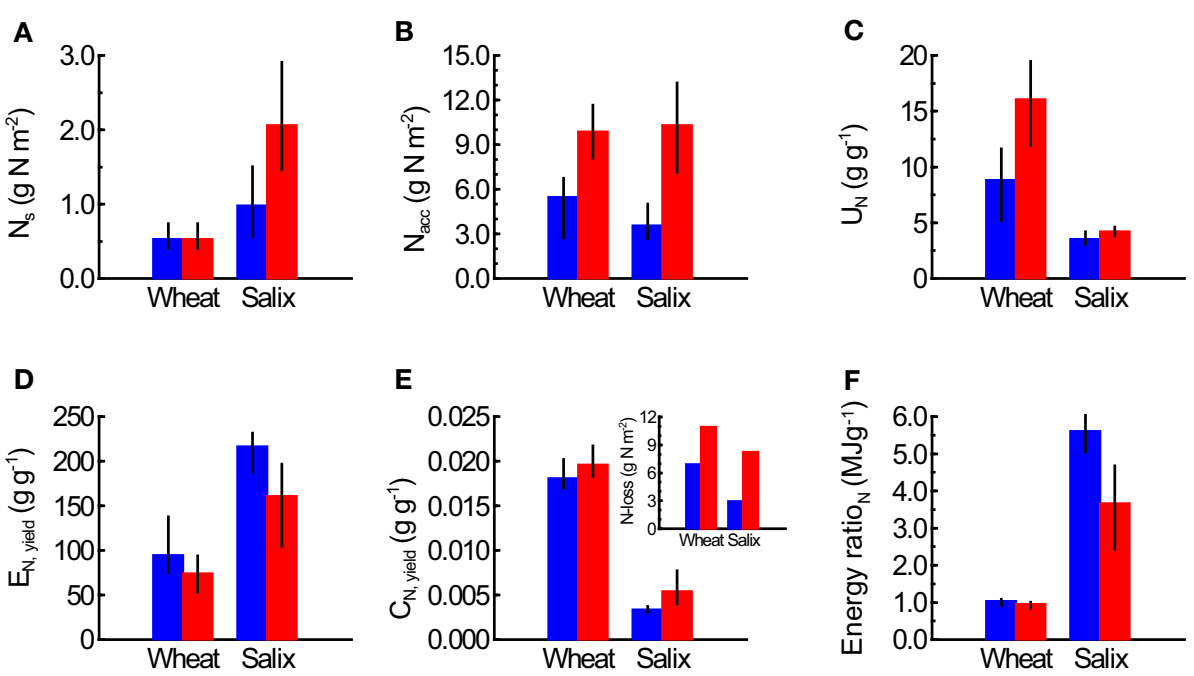

No nutrient fertilization NPK fertilization

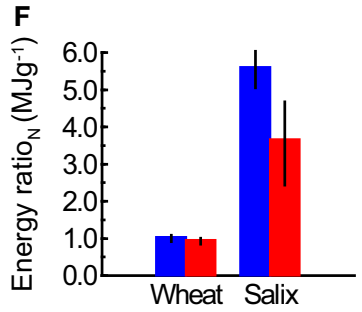

Wheat Salix
FIGURE 2 | Comparison of nitrogen (N) use efficiency aspects (sensu Weih et al., 2011) in six spring wheat varieties and six varieties of biomass willow (Salix, third year of first rotation) grown for energy conversion in Sweden under two nutrient fertilization regimes (no fertilization and NPK fertilization corresponding to $81 \mathrm{~kg} \mathrm{~N} \mathrm{ha}^{-1}$ in wheat and $90 \mathrm{~kg} \mathrm{~N} \mathrm{ha}^{-1}$ in willow). Error bars indicate ranges across variety means. (A) The initial crop $N$ pool at start $\left(N_{S}\right)$ of the growing season (seed grain $\mathrm{N}$ in wheat; shoot and root $\mathrm{N}$ in willow) per ground area. (B) The total $\mathrm{N}$ accumulated during the main growth period per ground area $\left(N_{\text {acc }}\right)$, which is the $\mathrm{N}$ pool by the end of main growth period minus $N_{\mathrm{s}}$. (C) The $N$ uptake efficiency $\left(U_{N}\right)$ expressing the mean $N$ accumulation in the crop during the main growth period per initial crop $\mathrm{N}$ pool. (D) The biomass yield specific $N$ efficiency ( $E_{N \text {, vied }}$ ) indicating the final grain or shoot biomass per mean $\mathrm{N}$ pool during the main growth period. (E) The $\mathrm{N}$ concentration in the grain or biomass yield $\left(C_{\mathrm{N} \text {, vield }}\right)$ used for energy conversion; and the mean $\mathrm{N}$ amount per ground area lost at harvest (inlet). (F) The N-based energy ratio (Energy ratio ${ }_{N}$ ) indicating the final energy output per $\mathrm{N}$ lost by biomass harvest; higher heating values of $18.4 \mathrm{MJ} \mathrm{kg}^{-1}$ (wheat without straw) and $18.7 \mathrm{MJ} \mathrm{kg}^{-1}$ (willow chips) were assumed (Börjesson and Tufvesson, 2011). Wheat grain biomass production was 4.1 (no fertilization) and $5.8 \mathrm{tha}^{-1}$ (NPK fertilization), and willow shoot biomass production at the end of the first 3-year rotation was 9 (no fertilization) and $16 \mathrm{t} \mathrm{ha}^{-1}$ (NPK fertilization). The wheat data are from Asplund et al. (2014), and the willow data are based on Weih and Nordh (2005). yield and quality traits toward an integrated perspective in which the modification of those traits is viewed in the light of concomitant changes in the ecological context affecting the sustainability of the production system, here resource depletion and greenhouse gas emissions.

\section{CARBON DYNAMICS}

Considering the environmental motivation of energy crops, an important breeding target for bioenergy crops should be increased carbon transfer from atmosphere to soil and enhanced carbon accumulation in soil. For example, carbon accumulation increased in formerly arable soils that were planted with fast-growing willow and poplar for 6-10 years (Kahle et al., 2005). Especially, the crop traits influencing root growth and decomposition will affect soil carbon dynamics. As fine roots have a short lifespan and rapid turnover, they contribute significantly to soil carbon cycling and thereby can influence soil carbon accumulation (Nadelhoffer et al., 1985; Fan and Guo, 2010). Fine root production and turnover are influenced by total plant carbon assimilation or crop productivity, and the relative carbon allocation to above and below ground plant parts including root exudates. Productivity and allocation patterns are genetically determined, as is leaf chemistry and leaf litter composition (e.g., leaf litter N content; Weih, 2009). The leaf litter quality influences litter decomposition and thereby the amount of soil carbon accumulation and also the composition of the accumulated carbon. The specific composition of soil carbon determines its longevity in the soil and thus the sustainability of any carbon accumulation seen in soils under energy crops (Baum et al., 2013).

As for other agricultural and forest crops, plant genotype, and the interaction with symbiotic fungi affect the above and below ground carbon allocation pattern also for energy crops, which opens a potential avenue for breeding toward increased carbon accumulation. For example, different varieties of biomass willows display large differences in resource allocation to leaves, shoots, and roots (Weih and Nordh, 2005), with potential genotype effects on soil carbon accumulation (Weih and Van Bussel, 2006). Resource allocation to different plant parts of these willows is also strongly affected by mycorrhizal symbionts colonizing the root systems. Mycorrhizal fungi consume up to one third of host plant assimilated carbon (Söderström, 2002; Hobbie, 2006), and the amount of carbon allocated below ground was consistently greater in Salix colonized with ectomycorrhizal fungi compared to non-mycorrhizal plants (Jones et al., 1991). Many energy crops are commonly forming mycorrhiza (e.g., commercial Salix plantations, Hrynkiewicz et al., 2012), which affect crop plant traits relevant for soil carbon accumulation both directly through the roots and indirectly through the influences on leaf and litter 
chemistry (Rooney et al., 2009). Mycorrhizal fungi interacting with energy crops such as Salix may thus significantly impact on soil carbon accumulation, but the interaction between the crop traits relevant for breeding and the microorganisms is currently difficult to predict due to the complex nature of the plant genotype vs. mycorrhizal fungi interaction (Fransson et al., 2013).

Breeding for increased soil carbon accumulation under energy crop stands is highly desirable and appears possible, because sufficient variation in relevant traits (e.g., root allocation, mycorrhiza colonization, leaf litter quality) appears to exist within the available germplasm of energy crops such as willow and poplar. Identification of the genetic basis for root allocation and leaf litter quality traits affecting soil carbon accumulation is feasible with the currently available methods, and can be targeted in breeding research. Also the identification of the genetic basis for the association with mycorrhizal fungi stimulating soil carbon accumulation should be possible; but breeding for increased carbon accumulation with the help of these microorganisms might be more difficult to realize due to the more complex ecological interactions involved.

\section{RESILIENCE AND TEMPORAL STABILITY}

Plant breeding usually focuses on yield or quality improvement under favorable conditions for growth in a short time scale (months to years) and at a plot to field scale, while environmental performance of a crop needs to be evaluated at longer time scales (years to decades) and at landscape to global scales (Wilson et al., 2014). At the longer time scales relevant in the evaluation of the environmental performance of energy crops, resilience, and temporal (yield) stability are important issues. Also in a climate change context, the development of crop production systems with high resilience and temporal (yield) stability are required to balance climate fluctuations. High crop performance under favorable conditions for growth frequently trades-off with improved stress tolerance important for yield stability and resilience, which is a challenge in crop breeding (Weih, 2003).

Enhanced resilience is often accomplished by complementary resource use along with reduced damage by pests and diseases, both are linked to the functional diversity in the production system (Tooker and Frank, 2012). For example, variety mixtures have been suggested to improve temporal yield stability and resilience, but plant breeding programs usually do not consider performance in complex and genetically mixed crop plantations. Another way to improve yield stability and resilience in cropping systems based on annual crops is the use of crop rotations (Wilson et al., 2014). Compared to monoculture systems, crop rotations can reduce external inputs through promoting efficient resource use as well as maintenance of long-term soil productivity (Zegada-Lizarazu and Monti, 2011). In the bioenergy and climate change contexts, these crop rotations should be aimed to keep soil tillage and external inputs to a minimum, while maximizing soil carbon accumulation (Smith et al., 1998). Also perennial energy crops such as Miscanthus or willow short rotation coppice have been suggested to improve resource use efficiency and soil carbon accumulation compared to annual crops (Tilman et al., 2002). However, there is currently very little knowledge on the resource use efficiency and carbon sequestration capacity in perennial systems as compared to annual systems when also crop rotations and mixtures are considered.
Plant breeding for improved resilience and temporal yield stability can be accomplished partly by increased focus on stress tolerance traits, which today is important in many energy crop breeding programs. However, especially in the resilience and yield stability context, plant traits need to be evaluated beyond the scale of individual plants and toward production system and ecosystem processes. Such a shift in perspective requires improved knowledge on the links between plant traits modified by breeding and their effects on the ecosystem processes relevant in the resilience and temporal stability context.

\section{CONCLUDING REMARKS}

The need for increased use of renewable energy sources, among them biomass production systems, is frequently motivated with environmental arguments. Today breeding of biomass crops is individual-plant and trait-based, whereas the evaluation of their environmental performance and sustainability is ecosystem based. In the future, we need to develop breeding strategies that link the modification of target traits in individual genotypes with the concomitant changes in the ecological context affecting natural resource use, soil carbon accumulation, temporal yield stability, and resilience.

Going beyond the promotion of individual genotypes grown in monoculture, it seems that genetically more diverse production systems with a wide range of traits are able to more efficiently utilize the niche space of the production system, thus reducing resource losses and enhancing environmental performance. Exploiting this diversity-driven improvement of resource use efficiency and environmental performance could be a useful strategy in the design of novel, sustainable agro-ecosystems (Malezieux et al., 2009), especially for growing energy crops. For that purpose, we need to first develop a theoretical framework to predict how single traits and trait combinations affect relevant ecosystem processes. This framework can then be adopted to target breeding strategies toward developing suites of genotypes with complementary traits that use resources more efficiently and enhance the environmental performance of the cropping system.

\section{ACKNOWLEDGMENTS}

This work was partly funded by the Swedish Energy Agency (project no. 36654-1).

\section{REFERENCES}

Anonymous. (2013). Dictionary.com. Dictionary.com Unabridged. Random House, Inc. Available at: http://dictionary.reference.com/browse/sustainability

Asplund, L., Bergkvist, G., and Weih, M. (2014). Proof of concept: nitrogen use efficiency of contrasting spring wheat varieties grown in greenhouse and field. Plant Soil 374, 829-842. doi:10.1007/s11104-013-1895-6

Baum, C., Eckhardt, K. U., Hahn, J., Weih, M., Dimitriou, I., and Leinweber, P. (2013). Impact of poplar on soil organic matter quality and microbial communities in arable soils. Plant Soil Environ. 59, 95-100.

Berndes, G., Hoogwijk, M., and Van den Broek, R. (2003). The contribution of biomass in the future global energy supply: a review of 17 studies. Biomass Bioenerg. 25, 1-28. doi:10.1016/S0961-9534(02)00185-X

Börjesson, P., and Tufvesson, L. (2011). Agricultural crop-based biofuels - resource efficiency and environmental performance including direct land use changes. J. Clean. Prod. 19, 108-120. doi:10.1016/j.jclepro.2010.01.001

Brodt, S., Six, J., Feenstra, G., Ingels, C., and Campbell, D. (2011). Sustainable agriculture. Nat. Educ. Knowl. 3, 1. 
Davidson, S. (2008). Sustainable bioenergy: genomics and biofuels development. Nat. Educ. 1, 175.

Fan, P. P., and Guo, D. L. (2010). Slow decomposition of lower order roots: a key mechanism of root carbon and nutrient retention in the soil. Oecologia 163, 509-515. doi:10.1007/s00442-009-1541-4

Fransson, P. M. A., Toljander, Y. K., Baum, C., and Weih, M. (2013). Host plantectomycorrhizal fungus combination drives resource allocation in willow: evidence for complex species interaction from a simple experiment. Ecoscience 20, 112-121. doi:10.2980/20-2-3576

Higman, S., Mayers, J., Bass, S., Judd, N., and Nussbaum, R. (2005). The Sustainable Forestry Handbook. London: Earthscan, 332.

Hobbie, E. A. (2006). Carbon allocation to ectomycorrhizal fungi correlates with belowground allocation in culture studies. Ecology 87, 563-569. doi:10.1890/050755

Hrynkiewicz, K., Toljander, Y. K., Baum, C., Fransson, P. M. A., Taylor, A. F. S., and Weih, M. (2012). Correspondence of ectomycorrhizal diversity and colonisation of willows (Salix spp.) grown in short rotation coppice on arable sites and adjacent natural stands. Mycorrhiza 22, 603-613. doi:10.1007/s00572-012-0437-z

Isebrands, J. G., and Karnosky, D. F. (2001). "Environmental benefits of poplar culture," in Poplar Culture in North America, Part A, eds D. I. Dickmann, J. G. Isebrands, J. E. Eckenwalder, and J. Richardson (Ottawa: NRC Research Press, National Research Council of Canada), 207-218.

Jaradat, A. A. (2010). Genetic resources of energy crops: biological systems to combat climate change. Aust. J. Crop Sci. 4, 309-323.

Jones, M. D., Durall, D. M., and Tinker, P. B. (1991). Fluxes of carbon and phosphorous between symbionts in willow ectomycorrhizas and their changes with time. New Phytol. 119, 99-106. doi:10.1111/j.1469-8137.1991.tb01012.x

Kahle, P., Baum, C., and Boelcke, B. (2005). Effect of afforestation on soil properties and mycorrhizal formation. Pedosphere 15, 754-760.

Kaien, R., Fumitaka, S., Jun, A., and Shigenori, M. (2012). Biomass yield and nitrogen use efficiency of cellulosic energy crops for ethanol production. Biomass Bioenerg. 37, 330-334. doi:10.1016/j.biombioe.2011.12.047

Karp, A., and Shield, I. (2008). Bioenergy from plants and the sustainable yield challenge. New Phytol. 179, 15-32. doi:10.1111/j.1469-8137.2008.02432.x

Kotchoni, S. O., and Gachomo, E. W. (2008). Biofuels production: a promising alternative energy for environmental cleanup and fuelling through renewable resources. J. Biol. Sci. 8, 693-701. doi:10.3923/jbs.2008.693.701

Long, S. P., Zhu, X.-G., Naidu, S. L., and Ort, D. R. (2006). Can improvement in photosynthesis increase crop yields? Plant Cell Environ. 29, 315-330. doi:10.1111/j.1365-3040.2005.01493.x

Malezieux, E., Crozat, Y., Dupraz, C., Laurans, M., Makowski, D., Ozier-Lafontaine, H., et al. (2009). Mixing plant species in cropping systems: concepts, tools and models. A review. Agron. Sustain. Dev. 29, 43-62. doi:10.1051/agro:2007057

Nadelhoffer, K. J., Aber, D., and Melillo, J. M. (1985). Fine roots, net primary production, and soil nitrogen availability: a new hypothesis. Ecology 66, 1377-1390. doi:10.2307/1939190

Perttu, K. L. (1993). Biomass production and nutrient removal from municipal wastes using willow vegetation filters. J. Sust. For. 1, 57-70. doi:10.1300/ J091v01n03_05

Rooney, D. C., Killham, K., Bending, G. D., Baggs, E., Weih, M., and Hodge, A. (2009). Mycorrhizas and biomass crops: opportunities for future sustainable development. Trends Plant Sci. 14, 542-549. doi:10.1016/j.tplants.2009.08.004

Schwartz, M. W., Brigham, C. A., Hoeksema, J. D., Lyons, K. G., Mills, M. H., and van Mantgem, P. J. (2000). Linking biodiversity to ecosystem function: implications for conservation ecology. Oecologia 122, 297-305. doi:10.1007/ s004420050035

Smith, P., Powlson, D. S., Glendining, M. J., and Smith, J. U. (1998). Preliminary estimates of the potential for carbon mitigation in European soils through no-till farming. Global Change Biol. 4, 679-685. doi:10.1046/j.1365-2486.1998.00185.x
Söderström, B. (2002). Challenges for mycorrhizal research into the new millennium. Plant Soil 244, 1-7. doi:10.1023/A:1020212217119

Tester, M., and Langridge, P. (2010). Breeding technologies to increase crop production in a changing world. Science 327, 818-822. doi:10.1126/science.1183700

Tilman, D., Cassman, K. G., Matson, P. A., Naylor, R., and Polasky, S. (2002). Agricultural sustainability and intensive production practices. Nature 418, 671-677. doi:10.1038/nature01014

Tooker, J. F., and Frank, S. D. (2012). Genotypically diverse cultivar mixtures for insect pest management and increased crop yields. J. Appl. Ecol. 49, 974-985. doi:10.1111/j.1365-2664.2012.02173.x

Weih, M. (2003). Trade-offs in plants and the prospects for breeding using modern biotechnology. New Phytol. 158, 7-9. doi:10.1046/j.1469-8137.2003.00716.x

Weih, M. (2009). Genetic and environmental variation in spring and autumn phenology of biomass willows (Salix spp.): effects on shoot growth and nitrogen economy. Tree Physiol. 29, 1479-1490. doi:10.1093/treephys/tpp081

Weih, M., Asplund, L., and Bergkvist, G. (2011). Assessment of nutrient use in annual and perennial crops: a functional concept for analyzing nitrogen use efficiency. Plant Soil 339, 513-520. doi:10.1007/s11104-010-0599-4

Weih, M., Didon, U. M. E., Rönnberg-Wästljung, A.-C., and Björkman, C. (2008). Integrated agricultural research and crop breeding: allelopathic weed control in cereals and long-term productivity in perennial biomass crops. Agric. Syst. 97, 99-107. doi:10.1016/j.agsy.2008.02.009

Weih, M., and Nordh, N.-E. (2005). Determinants of biomass production in hybrid willows and the prediction of field performance from pot studies. Tree Physiol. 25, 1197-1206. doi:10.1093/treephys/25.9.1197

Weih, M., and Rönnberg-Wästljung, A.-C. (2007). Shoot biomass is related to vertical leaf nitrogen gradient across Salix canopies. Tree Physiol. 27, 1551-1559. doi:10.1093/treephys/27.11.1551

Weih, M., and Van Bussel, L. (2006). "Effect of root and leaf allocation on soil carbon sequestration potential of Salix bioenergy plantations in Sweden," in Proceedings of the COST E38 Workshop Woody Root Processes, Revealing the Hidden Half, Sede Boqer, L2.

Whitham, T. G., Bailey, J. K., Schweitzer, J. A., Shuster, S. M., Bangert, R. K., LeRoy, C. J., et al. (2006). A framework for community and ecosystem genetics: from genes to ecosystems. Nature Rev. Gen. 7, 510-523. doi:10.1038/nrg1877

Wilson, D. M., Heaton, E. A., Schulte, L. A., Gunther, T. P., Shea, M. E., Hall, R. B., et al. (2014). Establishment and short-term productivity of annual and perennial bioenergy crops across a landscape gradient. Bioenergy Res. doi:10.1007/s12155-014-9409-9

Zegada-Lizarazu, W., and Monti, A. (2011). Energy crops in rotation. A review. Biomass Bioenerg. 35, 12-25. doi:10.1016/j.biombioe.2010.08.001

Conflict of Interest Statement: The authors declare that the research was conducted in the absence of any commercial or financial relationships that could be construed as a potential conflict of interest.

Received: 17 March 2014; paper pending published: 15 April 2014; accepted: 09 May 2014; published online: 22 May 2014.

Citation: Weih M, Hoeber S, Beyer F and Fransson P (2014) Traits to ecosystems: the ecological sustainability challenge when developing future energy crops. Front. Energy Res. 2:17. doi: 10.3389/fenrg.2014.00017

This article was submitted to Bioenergy and Biofuels, a section of the journal Frontiers in Energy Research.

Copyright $(2014$ Weih, Hoeber, Beyer and Fransson. This is an open-access article distributed under the terms of the Creative Commons Attribution License (CC BY). The use, distribution or reproduction in other forums is permitted, provided the original author(s) or licensor are credited and that the original publication in this journal is cited, in accordance with accepted academic practice. No use, distribution or reproduction is permitted which does not comply with these terms. 